\section{Ethnic variation in primary idiopathic macular hole surgery}

\begin{abstract}
Purpose The purpose of the study was to investigate the role of ethnicity on idiopathic macular holes (IMH) structure and surgical outcome. This was a retrospective review. Patients and methods Consecutive patients undergoing primary IMH surgery at two surgical sites of Moorfields Eye Hospital (London, UK) between April 2012 and June 2013. The main outcome measure was post surgical anatomical closure of IMH. Results Two hundred and twenty two primary IMH surgeries were undertaken. A standard procedure including pars plana vitrectomy, internal limiting membrane peeling, and gas tamponade was undertaken for all cases. $61.3 \%$ of patients were Caucasian, 21.2\% were South Asian, and 16\% were Afro-Caribbean. The mean minimum linear diameter (MLD) for our cohort was $434.6 \mathrm{mcm}$. Mean MLD was $395.3 \mathrm{mcm}$ in Caucasian patients, $490.0 \mathrm{mcm}$ in South Asians $(P=0.006)$, and $491.4 \mathrm{mcm}$ in AfroCaribbeans $(P=0.007)$. Regression analysis

demonstrated that MLD and Afro-Caribbean ethnicity were independent significant risk factors for surgical failure (OR: 1.01, $P<0.001$ and OR: $5.73, P=0.008$, respectively).

Conclusion South Asian and Afro-Caribbean patients present with larger IMH than Caucasians. In addition to IMH diameter, Afro-Caribbean ethnicity is an independent risk factor for surgical failure.

Eye (2017) 31, 708-712; doi:10.1038/eye.2016.296; published online 13 January 2017
\end{abstract}

${ }^{1}$ Department of Ophthalmology, Southend University Hospital Foundation Trust, Essex, UK

${ }^{2}$ Vitreoretinal Department, Moorfields Eye Hospital, London, UK

Correspondence: A Chandra, Department of Ophthalmology, Southend University Hospital Foundation Trust, Prittlewell Chase, Southend on Sea, Essex SSOORY, UK Tel: +44 (0)70 2435 555; Fax: +44 (0)20 75662052. E-mail: aman.chandra@ southend.nhs.uk

Received: 17 February 2016 Accepted in revised form: 23 November 2016;

Published online:

13 January 2017

\section{Introduction}

Idiopathic full thickness macular holes (IMH) are full thickness defects in the foveal neurosensory retina. ${ }^{1,2}$ Anteroposterior dynamic vitreomacular traction in combination with tangential contraction of the perifoveal vitreous cortex are thought to initiate macular hole formation. ${ }^{3}$ Although it is suggested that IMH occur predominantly over the age of 65 years ${ }^{4,5}$
A Chandra ${ }^{1,2}$, M Lai ${ }^{2}$, D Mitry², PJ Banerjee², H Flayeh ${ }^{2}$, G Negretti ${ }^{2}$, N Kumar ${ }^{2}$ and L Wickham $^{2}$ with preponderance in women, ${ }^{6}$ epidemiological information for IMH is limited. Although a small proportion of small IMH may resolve spontaneously $^{7}$ (up to $20 \%$ of Stage $1 \mathrm{IMH}$ and $<5 \%$ of larger holes), the vast majority progress. ${ }^{4}$ Surgical treatment was first described in $1991^{8}$ with the aim to relieve traction and halt intraretinal hydration, and the subretinal accumulation of vitreous fluid through the hole. ${ }^{9}$

The current surgical approach consists of pars plana vitrectomy (PPV) with or without internal limiting membrane (ILM) removal supplemented by intraocular gas or air tamponade. ${ }^{2}$ While most authors now report anatomical closure rates of over $90 \%{ }^{10}$ variations in surgical outcomes in different ethnicities have not previously been described. The aim of this study was to investigate this relationship.

\section{Materials and methods}

A retrospective analysis was carried out on all consecutive patients who underwent PPV for IMH repair at the vitreoretinal unit at Moorfields Eye Hospital at its two surgical centres at City Road (Central London) and at St George's University Hospital (South London) from April 2012 to June 2013. The primary outcome was defined as optical coherence tomography evidence of macular hole closure. Traumatic macular holes and those patients who had had vitrectomy prior to surgery for IMH repair were excluded.

Electronic patient database information collected included date of birth, sex, surgical date, surgeon grade (Consultant Surgeon, trainee under supervision), vitrectomy gauge, post-operative posturing instruction (in days), macular hole size (measured as minimum linear diameter (MLD)), and macular hole closure. In addition, data on patient socioeconomic status were ascertained using indices of multiple deprivation (IMD). This uses datazones for each patient, identified using individuals' postcodes, to give an overall relative deprivation score. ${ }^{11}$ 
Similar methodology has previously been used in vitreoretinal disease investigations. ${ }^{12}$ Ethnicity was defined by the patient choosing from a list including Caucasian, Afro-Caribbean, South Asian (Indian, Pakistani, Sri Lankan, and Bangladeshi), or other, as per routine demographic data collected for all our patients.

\section{Results}

Two hundred and twenty two IMH surgeries fulfilled the criteria for analysis (Table 1). One hundred and fifty three $(68.9 \%)$ of the patients were female, $136(61.3 \%)$ patients defined themselves as Caucasian, 47 patients $(21.2 \%)$ were South Asian, 37 (16.0\%) were Afro-Caribbean, and 2 $(0.9 \%)$ other. The mean MLD was $434.6 \mathrm{mcm}$ (range 104$1364 \mathrm{mcm}$, SD: $186.4 \mathrm{mcm})$. The mean MLD was 395.3 (95\% CI: 364.2-426.4) in Caucasian patients. Mean MLD in South Asian patients was 490.0 (95\% CI: 434.7-545.2; $P=0.006)$ and 491.4 (95\% CI: 414.3-568.6) in AfroCaribbeans $(P=0.007)$. Comparative analysis between south Asians and Afro-caribbeans was not statistically significant $(P=0.97)$. The distribution of ethnicity by deciles of IMD was noted to be unequal. The least deprived deciles (deciles 8-10) comprised $45.1 \%$ of Caucasians compared with only $19.1 \%$ of Asians and $5.4 \%$ of Afro-Caribbeans.

The majority $(81 \%)$ of surgeries were performed by supervised vitreoretinal fellows, with the remaining by consultant surgeons. The standard procedure involved PPV with ILM peel and intraocular tamponade. 97\% of surgeries were performed with $23 \mathrm{G}$ instrumentation, with the remaining 20G. Eighteen cases (8\%) had combined phacoemulsification surgery. All cases had gas tamponade; the majority (76\%) of cases utilised

Table 1 Baseline characteristics and gas tamponade utilised

\begin{tabular}{lr}
\hline Characteristics & $\mathrm{N}(\%)$ \\
\hline Surgeon $(\mathrm{N}=222)$ & \\
$\quad$ Consultant & $42(18.9)$ \\
Fellow & $180(81.1)$ \\
& \\
Gender $(\mathrm{N}=222)$ & $69(31.1)$ \\
$\quad$ Male & $153(68.9)$ \\
Female & \\
& \\
Gas tamponade $(\mathrm{N}=221)$ & $53(24)$ \\
SF6 & $168(76)$ \\
C3F8 & \\
Ethnicity (N=222) & $136(61.3)$ \\
Caucasian & $37(16.7)$ \\
Afro-Caribbean & $47(21.1)$ \\
Indian/Asian & $2(0.9)$ \\
Other &
\end{tabular}

Abbreviations: C3f8, octafluoropropane; SF6, sulphur heaxafluoride.
Octafluoropropane (C3F8) and remaining using sulphur hexafluoride.

Post-operative face down posturing regimes varied among surgeons with a mean duration of 5.2 days (SD: 2.7). The choice of tamponade and post-operative posturing regime was based on surgeon discretion.

Overall $193 \mathrm{IMH}$ surgeries resulted in anatomical closure (86.9\%). Mean MLD was $407.5 \mathrm{mcm}$ (95\% CI 382-432.7) for successful surgeries and $618.8 \mathrm{mcm}(95 \%$ CI 520.2-717.4) for failed primary surgeries. Success of surgery varied among the different ethnic origins (Table 2). Irrespective of IMH size, White Caucasian patients had $91.2 \%$ success rate, Afro-Caribbean patients $67.6 \%$, and South Asians 89.4\%. Table 2 highlights the $\mathrm{IMH}$ closure rate by size and ethnicity. Afro-Caribbean patients with large IMH ( $>400 \mathrm{mcm})$ had a higher failure rate than White Caucasians $(P=0.026)$.

We used binomial logistic regression to determine the effect of all variables on our primary outcome of hole closure following surgery. The following variables were included in the model: age, gender, ethnicity, index of multiple deprivation, gas used, combined phacoemulsification, days of post-operative posturing, and hole size. There were no significant interaction terms in the model. Deciles of deprivation was not a significant independent predictor of surgical failure in the unadjusted regression model. The likelihood ratio test $(P<0.001)$ strongly suggests that the variables chosen have an effect on the outcome and the goodness of fit statistic ( $\mathrm{H}-\mathrm{L}$ statistic; $P=0.38$ ) is insignificant, suggesting the model fit the data well.

The analysis (Supplementary Table) demonstrated that ethnic variation (Odds Ratio: 5.73 (Standard Error: 3.79), $P=0.008$ ) and MLD (Odds Ratio: 1.01 (Standard Error: $0.001), P<0.001)$ had a statistically significant effect on surgical IMH closure. Larger preoperative MLD and Afro-Caribbean ethnicity increased the chance of surgical failure.

\section{Discussion}

Primary IMH surgery was undertaken on 222 patients over 14 months between April 2012 and July 2013. The majority $(68.9 \%)$ of our patients were female, agreeing with population-based studies. ${ }^{6}$

Our overall success rate is comparable to other institutional data. ${ }^{13,14}$ MLD is thought to be one of the most important OCT parameters to predict surgical outcomes. ${ }^{15,16}$ The IMH operated on in this period were large (mean $435.1 \mathrm{mcm}$ ). ${ }^{17,18}$ We have confirmed that macular hole size is a significant predictor for surgical success; with smaller holes having higher success rates. ${ }^{19,20}$ This may be due to less pre-existing vitreoretinal traction in smaller IMH. Furthermore, size may act as a proxy for chronicity of macular holes. 
Table 2 The proportion of successful and unsuccessful surgery by ethnicity and hole size

\begin{tabular}{|c|c|c|c|c|}
\hline \multirow[t]{2}{*}{ Ethnicity } & \multicolumn{4}{|c|}{ Hole size } \\
\hline & $<250$ microns & 250-400 microns & $>400$ microns & Total \\
\hline \multicolumn{5}{|l|}{ Failed surgery ${ }^{\mathrm{a}}$} \\
\hline Caucasian & 1 & 1 & 6 & 8 \\
\hline Afro-Caribbean & 0 & 2 & 9 & 11 \\
\hline Asian & 0 & 0 & 5 & 5 \\
\hline Total & 1 & 3 & 20 & 24 \\
\hline \multicolumn{5}{|l|}{ Success $^{\mathrm{a}}$} \\
\hline Caucasian & 22 & 42 & 38 & 102 \\
\hline Afro-Caribbean & 3 & 8 & 13 & 24 \\
\hline Asian & 1 & 12 & 20 & 33 \\
\hline Other & 0 & 0 & 2 & 2 \\
\hline Total & 26 & 62 & 73 & 161 \\
\hline
\end{tabular}

Success rate $(N=185)$

\begin{tabular}{|c|c|c|c|}
\hline Caucasian & $95.70 \%$ & $97.70 \%$ & $86.40 \%$ \\
\hline Afro-Caribbean & $100 \%$ & $80 \%$ & $59.10 \%$ \\
\hline Asian & $100 \%$ & $100 \%$ & $80 \%$ \\
\hline
\end{tabular}

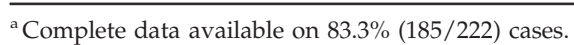

Macular hole duration was unfortunately not collected in this study.

Post-operative posturing instructions varied among surgeons, with a mean period of 5.2 days. There is considerable debate regarding the importance of posturing in achieving surgical success. ${ }^{17,21}$ Although posturing duration had no effect on outcome in this study, the power of the study may have been insufficient to elucidate any differences. ${ }^{22}$ Differences in adherence to posturing between ethnicities may have influenced the results and was unfortunately not determinable from this retrospective study. However, the independent role of ethnicity in therapeutic adherence is controversial, with no consensus to its influence. ${ }^{23}$

The ethnicity findings from our work are of particular interest. The majority of patients were White Caucasian (61.3\%) with $21.2 \%$ South Asians and $16.7 \%$ AfroCaribbean. This ethnicity-based demographic data is of interest and novel. According to the 2011 census, White Caucasians represent $59.8 \%$ of the London population. South Asians represent $18.4 \%$ and 'Black/African/ Caribbean/Black British' ethnic group 13.3\%. ${ }^{24}$ This study's proportions are, therefore, in keeping with the local population. A higher prevalence of certain ophthalmic conditions in alternate ethnic groups is well established, ${ }^{25-29}$ and our data is the first to give any such information on IMH. However, our data are not epidemiological, and must be interpreted cautiously.

Our investigations have demonstrated for the first time that Afro-Caribbean patients have a significantly greater risk of failure of IMH surgery than White Caucasian patients. Patients from South Asia had no such increased risk.

Within vitreoretinal disorders, we have previously shown a more severe ocular phenotype in South Asian patients with rhegmatogenous retinal detachment than White Caucasians. ${ }^{30}$ Gupta et al ${ }^{16}$ investigated ethnic variation in vitrectomy for complications of diabetes. They demonstrated no effect of patient ethnicity on visual outcome. Unfortunately effect of ethnicity on anatomical results was not discussed.

The aetiology of the effect of ethnicity on IMH surgery has not been previously described or discussed. Although a number of macular hole characteristics have been suggested as predictive of surgical success, ${ }^{31}$ size of hole is the most accepted risk factor. The MLD was greater in our Afro-Caribbean and South Asian patients. This may represent a delay in presentation of these populations. The subject of ethnic minority patients' access to healthcare in the $\mathrm{UK}^{32}$ and London, ${ }^{33}$ in particular, is challenging, and specific effects on ophthalmic disease is poorly understood. It is generally accepted that simply assessing for socioeconomic status is inadequate. ${ }^{34}$ Nonetheless, we have for the first time endeavoured to investigate this with ethnic variation in IMH using IMD. Our data suggest that a higher proportion of AfroCaribbean and South Asian patients were of lower socioeconomic status than White Caucasians. In spite of this, socioeconomic status was not an independent risk factor in the failure of IMH surgery.

Alternatively, ethnic-specific foveal anatomical factors may contribute to larger IMH. Furthermore, logistic 
regression demonstrated that Afro-Caribbean ethnicity was an independent risk factor for surgical failure. Data from our institutions have previously demonstrated that Afro-Caribbean patients undergoing vitrectomy for complications of diabetes have broader and more anterior vitreoretinal adhesions. ${ }^{35}$ Of particular relevance, central macular thickness and, particularly, foveal thickness has been demonstrated to be thinner in Afro-Caribbeans than White Caucasians. ${ }^{36-38}$ More recently Bafiq et $a l^{39}$ have demonstrated that Afro-Caribbeans had wider and deeper foveal pits compared with South Asians and Caucasians. It is likely that other features of either the $\mathrm{IMH}$ itself or the vitreoretinal interface itself may show ethnic variation. In combination, these may contribute to the greater risk of failure of surgery in Afro-Caribbean patients, particularly in larger IMHs, as our data has shown. Our findings may influence surgeons' choice of intraocular tamponade or post-operative posturing in Afro-Caribbean patients. Studies investigating these variables in macular hole surgical success should consider patient ethnicity. Furthermore, with the introduction of new treatment paradigms for $\mathrm{IMH}^{40}$ it is perhaps prudent that vitreoretinal units that treat multi racial populations consider ethnicity when counselling patients with regards to their treatment options.

The limitations of our study must be acknowledged. This was single centred and retrospective. Axial length data were not available for analysis. It is suggested that high myopia may limit surgical success. ${ }^{41}$ However, AfroCaribbeans are thought to have a lower burden of myopia than other ethnicities. ${ }^{42,43}$ Therefore, it is unlikely that this limitation would have influenced our results significantly. Notwithstanding the limitations, our data is one of the largest on this topic to date, and contributes significantly to the understanding of the influence of ethnic variation on foveal disease.

\section{Summary}

What was known before

- It is suggested that idiopathic macular holes (IMH) occur predominantly over the age of 65 years with preponderance in women; however, epidemiological information for IMH is limited.

What this study adds

- We have investigated, for the first time, differences in idiopathic macular holes and surgical outcomes for IMH between three ethnic groups. We have demonstrated that South Asian and Afro-Caribbean patients have larger IMH compared with White Caucasians.

- Furthermore Afro-Caribbean ethnicity was an independent risk factor for surgical failure.

\section{Conflict of interest}

The authors declare no conflict of interest.

\section{Acknowledgements}

We acknowledge a proportion of their financial support from the Department of Health through the award made by the National Institute for Health Research to Moorfields Eye Hospital NHS Foundation Trust and UCL Institute of Ophthalmology for a Biomedical Research Centre for Ophthalmology.

\section{Disclaimer}

The views expressed in this publication are those of the authors and not necessarily those of the Department of Health.

\section{References}

1 Gass JD. Idiopathic senile macular hole. Its early stages and pathogenesis. Arch Ophthalmol 1988; 106(5): 629-639.

2 Steel DH, Lotery AJ. Idiopathic vitreomacular traction and macular hole: a comprehensive review of pathophysiology, diagnosis, and treatment. Eye 2013; 27 (Suppl 1): S1-21.

3 Smiddy WE, Flynn HW Jr. Pathogenesis of macular holes and therapeutic implications. Am J Ophthalmol 2004; 137(3): 525-537.

4 Chew EY, Sperduto RD, Hiller R, Nowroozi L, Seigel D, Yanuzzi LA et al. Clinical course of macular holes: the Eye Disease Case-Control Study. Arch Ophthalmol 1999; 117(2): 242-246.

5 Johnson MW, Van Newkirk MR, Meyer KA. Perifoveal vitreous detachment is the primary pathogenic event in idiopathic macular hole formation. Arch Ophthalmol 2001; 119(2): 215-222.

6 McCannel CA, Ensminger JL, Diehl NN, Hodge DN. Population-based incidence of macular holes. Ophthalmology 2009; 116(7): 1366-1369.

7 Hikichi T, Yoshida A, Akiba J, Trempe CL. Natural outcomes of stage 1, 2, 3, and 4 idiopathic macular holes. Br J Ophthalmol 1995; 79(6): 517-520.

8 Kelly NE, Wendel RT. Vitreous surgery for idiopathic macular holes. Results of a pilot study. Arch Ophthalmol 1991; 109(5): 654-659.

9 Tornambe PE. Macular hole genesis: the hydration theory. Retina 2003; 23(3): 421-424.

10 Spiteri Cornish K, Lois N, Scott NW, Burr J, Cook J, Boachie C et al. Vitrectomy with internal limiting membrane peeling versus no peeling for idiopathic full-thickness macular hole. Ophthalmology 2014; 121(3): 649-655.

11 Department for Communities and Local Government. English Indices of Deprivation 2015. 2015. Available at: https:/ / www.gov.uk/government/statistics/ englishindices-of-deprivation-2015 (accessed in 2016).

12 Mitry D, Charteris DG, Yorston D, Siddiqui MA, Campbell H, Murphy AL et al. The epidemiology and socioeconomic 
associations of retinal detachment in Scotland: a two-year prospective population-based study. Invest Ophthalmol Vis Sci 2010; 51(10): 4963-4968.

13 Tognetto D, Grandin R, Sanguinetti G, Minutola D, Di Nicola M, Di Mascio R et al. Internal limiting membrane removal during macular hole surgery: results of a multicenter retrospective study. Ophthalmology 2006; 113(8): 1401-1410.

14 Uemoto R, Yamamoto S, Aoki T, Tsukahara I, Yamamoto T, Takeuchi S. Macular configuration determined by optical coherence tomography after idiopathic macular hole surgery with or without internal limiting membrane peeling. Br J Ophthalmol 2002; 86(11): 1240-1242.

15 Ullrich S, Haritoglou C, Gass C, Schaumberger M, Ulbig MW, Kampik A. Macular hole size as a prognostic factor in macular hole surgery. Br J Ophthalmol 2002; 86(4): 390-393.

16 Gupta B, Sivaprasad S, Wong R, Laidlaw A, Jackson TL, McHugh D et al. Visual and anatomical outcomes following vitrectomy for complications of diabetic retinopathy: the DRIVE UK study. Eye (Lond) 2012; 26(4): 510-516.

17 Chandra A, Charteris DG, Yorston D. Posturing after macular hole surgery: a review. Ophthalmologica 2011; 226(Suppl 1): 3-9.

18 Duker JS, Kaiser PK, Binder S, de Smet MD, Gaudric A, Reichel E et al. The International Vitreomacular Traction Study Group classification of vitreomacular adhesion, traction, and macular hole. Ophthalmology 2013; 120(12): 2611-2619.

19 Wakely L, Rahman R, Stephenson J. A comparison of several methods of macular hole measurement using optical coherence tomography, and their value in predicting anatomical and visual outcomes. Br J Ophthalmol 2012; 96(7): 1003-1007.

20 Salter AB, Folgar FA, Weissbrot J, Wald KJ. Macular hole surgery prognostic success rates based on macular hole size. Ophthalmic Surg Lasers Imaging 2012; 43(3): 184-189.

21 Solebo AL, Lange CA, Bunce C, Bainbridge JW. Face-down positioning or posturing after macular hole surgery. Cochrane Database Syst Rev 2011;(12): CD008228.

22 Yorston D, Siddiqui MA, Awan MA, Walker S, Bunce C, Bainbridge JW. Pilot randomised controlled trial of facedown posturing following phacovitrectomy for macular hole. Eye 2012; 26(2): 267-271

23 Jin J, Sklar GE, Min Sen Oh V, Chuen Li S. Factors affecting therapeutic compliance: a review from the patient's perspective. Ther Clin Risk Manag 2008; 4(1): 269-286.

24 Office National Statistics. Available at: http://www.ons. gov.uk/ (accessed on 8 February 2015).

25 Qiu M, Wang SY, Singh K, Lin SC. Racial disparities in uncorrected and undercorrected refractive error in the United States. Invest Ophthalmol Vis Sci 2014; 55: 6996-7005.

26 Cheng JW, Zong Y, Zeng YY, Wei RL. The prevalence of primary angle closure glaucoma in adult Asians: a systematic review and meta-analysis. PLoS One 2014; 9(7): e103222.

27 Scanlon PH, Aldington SJ, Stratton IM. Epidemiological issues in diabetic retinopathy. Middle East Afr J Ophthalmol 2013; 20(4): 293-300.
28 Chandra A, Brookes J. Ethnicity and paediatric optic discs. Ophthalmic Physiol Opt 2012; 32(3): 252.

29 Chandra A, Arno G, Williamson K, Sergouniotis PI, Preising MN, Charteris DG et al. Expansion of ocular phenotypic features associated with mutations in ADAMTS18. JAMA Ophthalmol 2014; 132(8): 996-1001.

30 Chandra A, Banerjee P, Davis D, Charteris D. Ethnic variation in rhegmatogenous retinal detachments. Eye (Lond) 2015; 29(6): 803-807.

31 Hoerauf $\mathrm{H}$. Predictive values in macular hole repair. $\mathrm{Br} \mathrm{J}$ Ophthalmol 2007; 91(11): 1415-1416.

32 Fund K Access to Health Care and Minority Ethnic Groups. 2006. Available at: http:/ /www.kingsfund.org.uk/ sites/files/kf/field/field_publication_file/access-to-healthcare-minority-ethnic-groups-briefing-kings-fund-february2006.pdf.

33 Atkinson MCM, Clay D, Johnson M, Owen D, Szczepura A Systematic Review of Ethnicity and Health Service Access for London. 2001. Available at: mighealth.net/uk/images/ 5/56/System.doc. (accessed in 2015).

34 Szczepura A. Access to health care for ethnic minority populations. Postgrad Med J 2005; 81(953): 141-147.

35 Yorston D, Wickham L, Benson S, Bunce C, Sheard R, Charteris D. Predictive clinical features and outcomes of vitrectomy for proliferative diabetic retinopathy. $\mathrm{Br} \mathrm{J}$ Ophthalmol 2008; 92(3): 365-368.

36 Wagner-Schuman M, Dubis AM, Nordgren RN, Lei Y, Odell D, Chiao $\mathrm{H}$ et al. Race- and sex-related differences in retinal thickness and foveal pit morphology. Invest Ophthalmol Vis Sci 2011; 52(1): 625-634.

37 Asefzadeh B, Cavallerano AA, Fisch BM. Racial differences in macular thickness in healthy eyes. Optom Vis Sci 2007; 84 (10): 941-945.

38 Girkin CA, McGwin Jr G, Xie A, Deleon-Ortega J. Differences in optic disc topography between black and white normal subjects. Ophthalmology 2005; 112(1): 33-39.

39 Bafiq R, Mathew R, Pearce E, Abdel-Hey A, Richardson M, Bailey $\mathrm{T}$ et al. Age, sex, and ethnic variations in inner and outer retinal and choroidal thickness on spectral-domain optical coherence tomography. Am J Ophthalmol 2015; 160(5): 1034-1043.e1.

40 Amoaku W, Cackett P, Tyagi A, Mahmood U, Nosek J, Mennie G et al. Redesigning services for the management of vitreomacular traction and macular hole. Eye 2014; 28(Suppl 1): S1-10.

41 Alkabes M, Pichi F, Nucci P, Massaro D, Dutra Medeiros M, Corcostegui $\mathrm{B}$ et al. Anatomical and visual outcomes in high myopic macular hole (HM-MH) without retinal detachment: a review. Graefes Arch Clin Exp Ophthalmol 2014; 252(2): 191-199.

42 Hyman L, Gwiazda J, Hussein M, Norton TT, Wang Y, Marsh-Tootle $\mathrm{W}$ et al. Relationship of age, sex, and ethnicity with myopia progression and axial elongation in the correction of myopia evaluation trial. Arch Ophthalmol 2005; 123(7): 977-987.

43 National Eye Institute (NEI). Myopia. Available at: https:/ / nei.nih.gov/eyedata/myopia (accessed on 2015). 